\title{
TNF $\alpha$-induced Up-regulation of Ascl2 Affects the Differentiation and Proliferation of Neural Stem Cells
}

\author{
Zhongfeng Liu ${ }^{1,2,3}$, Xuan Wang ${ }^{1,2,3}$, Kewen Jiang ${ }^{4}$, Xunming Ji ${ }^{5}$, Y. Alex Zhang ${ }^{1, *}$, Zhiguo \\ Chen ${ }^{1,2,3, *}$
}

${ }^{1}$ Cell Therapy Center, Beijing Institute of Geriatrics, Xuanwu Hospital, Capital Medical University, and Key Laboratory of Neurodegeneration, Ministry of Education, Beijing, China

${ }^{2}$ Center of Neural Injury and Repair, Beijing Institute for Brain Disorders, Beijing, China

${ }^{3}$ Center of Parkinson's Disease, Beijing Institute for Brain Disorders, Beijing, China

${ }^{4}$ Department of Neurology, the Children's Hospital School of Medicine, Zhejiang University, Hangzhou, China

${ }^{5}$ Department of Neurosurgery, Xuanwu Hospital, Capital Medical University, Beijing, China

[Received August 20, 2018; Revised October 17, 2018; Accepted October 28, 2018]

\begin{abstract}
The molecular mediators underlying the effects of inflammation on neural stem cells (NSCs) are not fully characterized. In this study, we identified Ascl2 as a downstream basic helix-loop-helix (bHLH) transcription factor in NSCs following exposure to TNF $\alpha$. Under normal conditions, Ascl2 expression is inhibited at post-transcriptional levels by miR-26a, which targets the 3 ' untranslated region (UTR) of Ascl2. Upon exposure to TNF $\alpha$, miR-26a expression is reduced, which leads to up-regulation of Ascl2. Overexpression of Ascl2 promotes neuronal differentiation, reduces proliferation, and increases the level of cleaved CASPASE 3 in NSCs, as observed in the in vitro and in ovo experiments. Ascl2 may serve in NSCs as a standby factor that readily responds to $\mathrm{TNF} \alpha$, which is often induced in inflammatory situations. In a chronic inflammatory condition with consistent up-regulation of TNFa, overexpression of $A s c l 2$ may inhibit neurogenesis as a net result.
\end{abstract}

Key words: Ascl2, neural stem cells, miR-26a, in ovo, TNFa

Neural stem cells (NSCs) and NSC derivatives possess potentials for treatment of various neurological disorders/diseases, such as Parkinson's disease, amyotrophic lateral sclerosis (ALS), and spinal cord injury, etc. Autologous vs. allogeneic donor cells/grafts have their pros and cons; and in a foreseeable future, the two would co-exist in medical practices. Our previous study has shown that, allogeneic NSCs can trigger immune recognition when transplanted into the native neurogenic areas in mouse brains, although brain has been considered an immune-privileged organ [1]. The immunological responses mediated mainly through microglia and microglia-secreted cytokines, such as $\mathrm{TNF} \alpha$, exert influences on both the incoming grafts and the endogenous NSCs [1,2]. Particularly, the effects of $\mathrm{TNF} \alpha$ are context-dependent and the net result of TNF $\alpha$ signaling pathway can be either deleterious or beneficial in different models, for example, in allograft transplantation models and in cranial irradiation models [2]. The contribution of inflammatory components in modulation of neurogenesis seems to be complex, and the downstream mediators in acute and chronic inflammation have not been fully characterized.

Achaete-scute complex homolog 2 (Ascl2) is a basic helix-loop-helix (bHLH) transcription factor, a mammalian member of the achaete-scute family. Ascl2 expression is relatively high in placenta, Schwann cells, and intestine stem cells, but is normally low or

*Correspondence should be addressed to: Drs. Zhiguo Chen (chenzhiguo@gmail.com) or Y. Alex Zhang (yaz@bjsap.org), Cell Therapy Center, Beijing Institute of Geriatrics, Xuanwu Hospital, Capital Medical University, Beijing, China

Copyright: () 2018 Liu Z et al. This is an open-access article distributed under the terms of the Creative Commons Attribution License, which permits unrestricted use, distribution, and reproduction in any medium, provided the original author and source are credited. 
undetectable in other tissues/organs [3-5]. In murine placentas, Ascl 2 is necessary for the specification of spongiotrophoblast cells [6]. In mouse peripheral nervous system, Ascl2 is expressed in Schwann cells and serves as a negative regulator for Schwann cell proliferation. After sciatic nerve lesion, Ascl2 level in Schwann cells is downregulated to promote proliferation [4]. In mouse small intestines, Ascl2 is considered as an intestine stem cell marker whose expression is critical for maintaining the stemness of intestine stem cells [5]. And ectopic overexpression of Ascl2 seems to be implicated in colorectal cancer [7-9]. However, in Drosophila posterior midgut, Scute plays a different role. Transient Scute activation instructs intestine stem cells to assume asymmetric divisions, which generates a stem cell and an enteroendocrine progenitor cell. Scute activity then guides each enteroendocrine progenitor cell to divide exactly once before terminally differentiating to a pair of enteroendocrine cells [10]. The seemingly different roles in the above studies suggest that the complex functions of Ascl2 may be tissue-specific and microenvironmentdependent.

In the current study, we found that Ascl2 is induced in NSCs by treatment with pro-inflammatory cytokine $\mathrm{TNF} \alpha$, and Ascl2 affects the proliferation and differentiation of NSCs.

\section{MATERIALS AND METHODS}

\section{Neural stem cell culture}

Mouse NSCs were isolated from postnatal day 0 pups of C57BL/6 background provided by the Jackson Laboratory. Using methods previously described [2], the cerebellum and brain stem were removed from whole brains of neonatal animals, the remnant tissues were enzymatically digested and triturated by pipetting. The resultant cell suspension was centrifuged and resuspended in growth medium-Neurobasal A supplemented with B-27 without vitamin A, L-glutamax, FGF2 and EGF (ThermoFisher, Waltham, MA, USA), to allow for selective survival of NSCs and formation of neurospheres. When neurospheres grew bigger, the spheres were passaged by treatment with Accutase (ThermoFisher). For monolayer culture, the spheres were seeded in plates coated with poly-D-lysine/laminin to allow for attachment and spreading. An evenly distributed monolayer culture could be achieved after two cell passages.

\section{Pathway focused array}

To examine the transcriptional changes in stem cellrelated genes downstream of TNF $\alpha$ treatment in murine
NSCs, we performed a pathway focused array (GEArray Express Mouse Neurogenesis and Neural Stem Cell Microarray, EMM-404). NSCs of passage number 7 (P7) were cultured as monolayer in a differentiation medium for $5 \mathrm{~h}$ with or without $20 \mathrm{ng} / \mathrm{ml} \mathrm{TNF} \alpha$ and/or SN50 (an inhibitor that blocks NF-kB to translocate to nucleus). Two hundred and eighty-one genes related to neural stem cells plus Gapdh as an internal control gene were analyzed.

\section{Western Blotting}

NSCs were lysed by cold RIPA lysis buffer (Applygen Technologies, Beijing, China), and the protein concentrations were determined by using BCA Protein Assay Reagent (ComWin Biotech, Beijing, China). The lysates were separated by $10 \%$ SDS-PAGE and transferred electrophoretically onto polyvinylidene difluoride membranes. After being blocked with 5\% nonfat milk in TBST, the membranes were incubated with the primary antibody against ASCL2 (MAB4418, Merk Millipore, Burlington, Massachusetts, USA). After incubation with an HRP-conjugated secondary antibody (ComWin Biotech), the signals were measured by using ECL reagents (Merk Millipore) and visualized by the ChemiDoc MP imaging system. GAPDH (ComWin Biotech) was used as an internal control.

\section{Quantitative Real-Time PCR (qPCR)}

To detect mRNA and miRNA from NSCs, RNA was harvested from cells using the RNEasy kit (Qiagen, Duesseldorf, Germany) or TRIzol reagent (ThermoFisher) according to the previously instruction [11]. Total cDNA was obtained by using PrimeScript ${ }^{\mathrm{TM}}$ RT reagent (Takara, Tokyo, Japan). Quantitative RT-PCR was performed using SYBR Premix Ex Taq II (Takara). Gapdh was used as an internal control. The miRNAspecific cDNA generation and RT-PCR were performed using Hairpin-it TM miRNAs RT-PCR Quantitation Kit (GenePharma, Shanghai, China), and all the Taqman probes listed in Table S2 were synthesized by GenePharma. Signals were detected using an LC480 Real-Time PCR system (Roche, Basel, Switzerland).

\section{Cell cycle analysis}

Mouse NSCs were seeded on PDL/Laminin-coated plates in medium supplemented with $4 \mathrm{ng} / \mathrm{ml}$ polybrene solution with pBMN-Ascl2-GFP (retrovirus) or pBMN-GFP (retrovirus) for $24 \mathrm{~h}$. The retroviral vector $\mathrm{pBMN}-$ Ascl2GFP was constructed by inserting the mouse Ascl 2 coding sequence $(800 \mathrm{bp})$. After the virus was washed off, the cells were incubated in new medium for $24 \mathrm{~h}$, then 
dissociated with Accutase, and re-suspended into single cell solution. GFP-positive cells were sorted by using BD FACSAria II (Becton Dickinson, CA, USA). Five hours later, cells were fixed in cold $70 \%$ ethanol for $2 \mathrm{~h}$ at $4{ }^{\circ} \mathrm{C}$. Prior to flow cytometric assay, NSCs were incubated with $100 \mu \mathrm{g} / \mathrm{ml}$ RNase for $30 \mathrm{~min}$ and then with $100 \mathrm{ug} / \mathrm{ml}$ Propidium Iodide (PI, Sigma-Aldrich) for $15 \mathrm{~min}$. In order to reduce the loss of cells during the process, $1 \%$ BSA was added to the washing buffer.

\section{BrdU labeling}

NSCs were infected with pBMN-Ascl2-GFP virus. After sorting, cells were seeded in PDL/Laminin-coated coverslips in proliferation medium. Twenty-four hours later, the culture was pulsed with $5 \mu \mathrm{M}$ BrdU for $1 \mathrm{~h}$, followed by medium change and cultured for another 15 $\mathrm{h}$. Then the cells were fixed in $4 \%$ paraformaldehyde (PFA) for $10 \mathrm{~min}$ at room temperature. The staining procedure for BrdU has been described in a previously published study [11].

\section{In ovo electroporation of chicken embryos}

As previously described [12, 13], fertilized eggs were incubated for $36 \mathrm{~h}$ on one side in a humidified incubator at $37{ }^{\circ} \mathrm{C}$ to reach Hamburger-Hamilton (HH) stage 10. A pencil was used to mark the top of the egg. At the small end of the egg, approximately $5 \mathrm{ml}$ albumin was removed carefully by using a syringe with $18 \mathrm{G}$ needle, and then the hole was sealed with a small piece of tape. The top of the egg was covered with another piece of tape (about $4 \times 4$ $\mathrm{cm})$. A hole of appropriate size was cut for windowing. Afterwards, 5\% Fast Green was injected under the embryo to facilitate visualization of the embryo. Plasmid solution was made by mixing $0.8 \mu \mathrm{l}$ of $5 \%$ Fast Green and $7.2 \mu \mathrm{l}$ of pCIG-Ascl2-GFP or pCIG-GFP $(3 \mu \mathrm{g} / \mu \mathrm{l})$ and was injected into the lumen of the neural tube until the dye filled the entire space. For electroporation, the two electrodes spaced $3 \mathrm{~mm}$ apart were placed parallel to each side of the embryo. Five times of pulses were conducted at 18 volts at 1 second intervals and lasted for 50 milliseconds. Presence of bubbles close to the negative electrode suggested that the electroporation system had properly worked. Consequently, the eggs were sealed with tape and returned to the incubator. After 24 or $48 \mathrm{~h}$, the embryos with GFP fluorescence were collected for further analysis. A small hole was made at the top of the brain and the embryos were immersed in 4\% PFA for $1 \mathrm{~h}$ at room temperature, followed by transferring into $30 \%$ sucrose solution diluted in $0.1 \mathrm{M}$ phosphate buffer. After sinking to the bottom, the embryos were frozen in OCT embedding solution, cut into slides $(20-25 \mu \mathrm{m})$ and stored at $-80^{\circ} \mathrm{C}$.

\section{Immunohistochemistry}

The chicken embryo sections or fixed cells were immunostained as previously described [14]. The following primary antibodies were used in the study: Rat anti-BrdU (1:1000, OBT0030CX, Bio-Rad), mouse antiNEUN (1:500, MAB377, Millipore), goat anti-DCX (1:500, SC8066, Santa Cruz Biotechnology, Dallas, USA ), rabbit anti-cleaved CASPASE3 (1:500, 9661, Cell Signaling Technology), mouse anti-NESTIN (1:500, 611658, BD Biosciences, San Jose, USA), goat antiSOX2 (1:1000, SC17320, Santa Cruz Biotechnology), Rabbit anti-P65 (1:500, Santa Cruz Biotechnology). Donkey anti-mouse, rat, goat or rabbit antibodies conjugated to FITC, Cy3, Cy5 or biotin were used at 1:500 dilution (Jackson ImmunoResearch, West Grove, USA).

\section{Confocal microscopy}

A Leica TCS SP5 confocal microscope was used for analysis. Appropriate gain and black level settings were determined on control tissues stained with secondary antibodies alone. Upper and lower thresholds were always set using the range indicator function to minimize data loss through under or over saturation. Upper and lower thresholds were then held constant for all samples when scoring tissues or cells for a given experiment.

\section{Luciferase reporter assay}

Luciferase reporter experiments were performed in the HEK293 or NIH3T3 cells. The wild type and mutant 3' UTR segment of the Ascl 2 gene was amplified by PCR and inserted to replace the original 3' UTR of the LuxA gene in the vector GP-miRGLO (GenePharma). Using Lipofectamine ${ }^{\circledR} \quad 2000 \quad$ Transfection Reagent (ThermoFisher), cells were transfected with $50 \mathrm{ng}$ Ascl23'UTR or Ascl2-3'UTR-MUT (mutation) plasmid and 100 $\mathrm{nM}$ miR-26a-5p mimics or control miRNA (NC) (GenePharma). Cells were lysed $24 \mathrm{~h}$ post-transfection, and luciferase activity was measured by using dual luciferase assays (E1910, Promega, Wisconsin-Madison, USA) following the manufacturer's protocol.

\section{Statistical analysis}

All experiments were performed at least three times. The results of one representative experiment were shown in the figures. Data were expressed as means \pm SEM and were analyzed by using student t-test or one-way analysis of variance (ANOVA) using Prism 5.0 GraphPad software (GraphPad, San Diego, CA, USA). A p value less than 0.05 was considered statistically significant. 
A

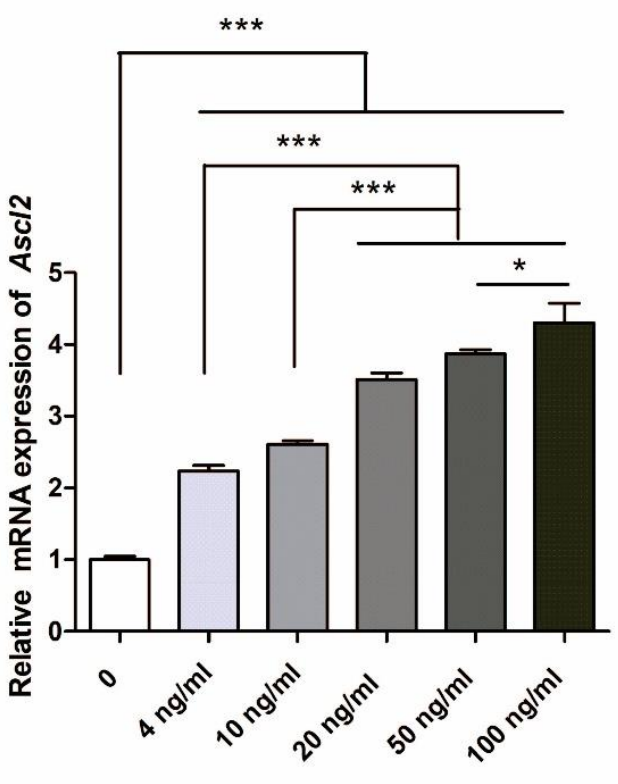

Pro

C

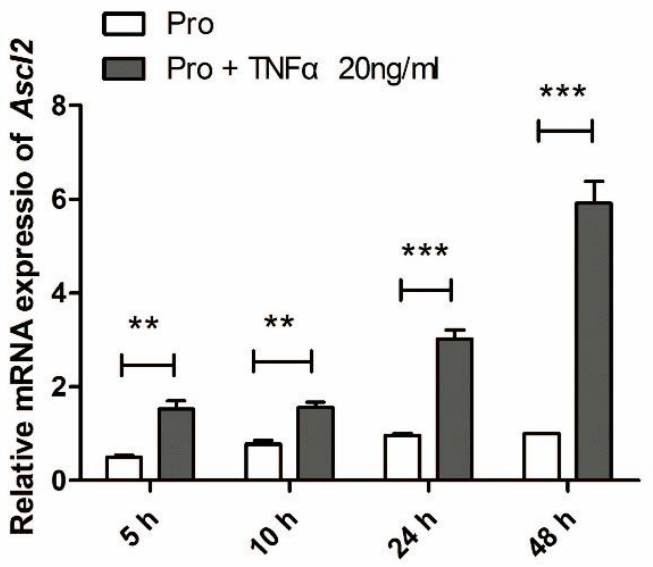

$E$

Pro + TNFa $(\mathrm{ng} / \mathrm{ml}) 48 \mathrm{~h}$

$\begin{array}{llllll}0 & 4 & 10 & 20 & 50 & 100\end{array}$

ASCL2 GAPDH
B

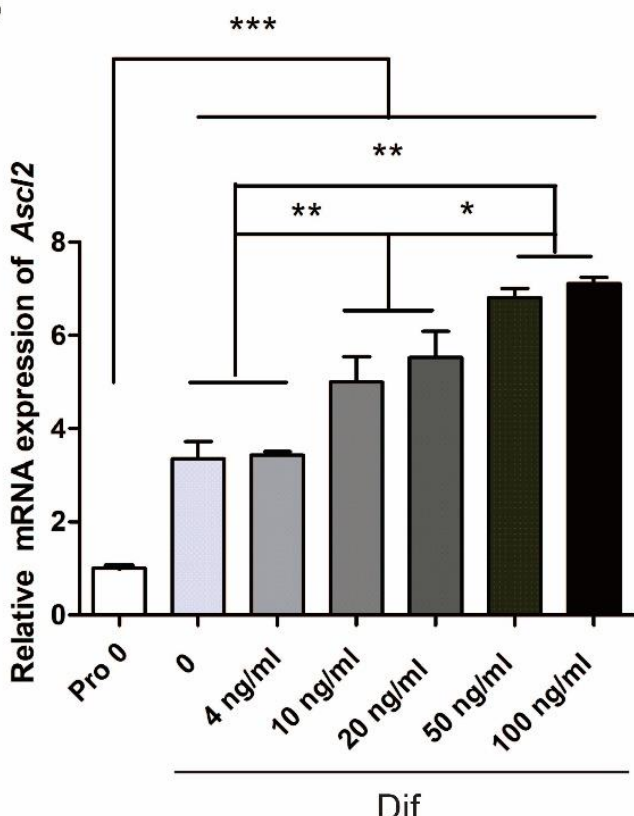

D

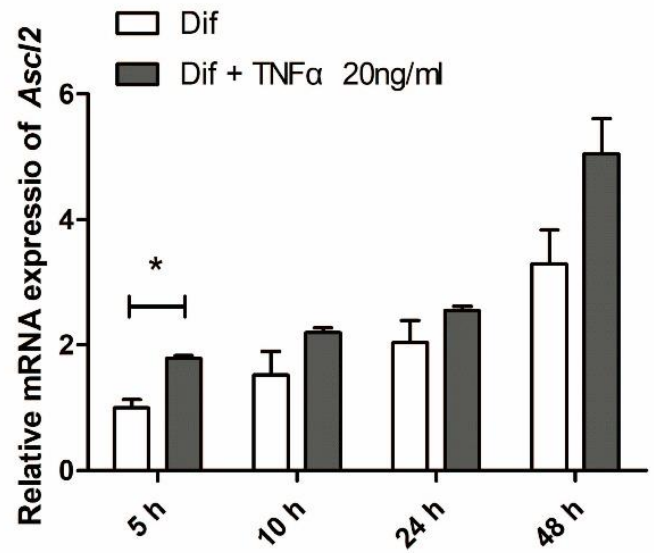

F

Dif + TNFa (ng/ml) $48 \mathrm{~h}$

$\begin{array}{llllll}0 & 4 & 10 & 20 & 50 & 100\end{array}$

ASCL2 GAPDH

Figure 1. Exposure to TNF $\alpha$ up-regulates Ascl2 expression in neural stem cells (NSCs). (A-B) Mouse NSCs were treated with different concentrations of TNF $\alpha$ in proliferation (A) and differentiation (B) medium for $48 \mathrm{~h}$, and $A s c l 2$ mRNA expression levels were examined. The results were normalized to NSCs without TNF $\alpha$. See also Figure S2. Pro: proliferation, Dif: differentiation. ( $\mathrm{n}=3$ ). (C-D) NSCs were treated with $20 \mathrm{ng} / \mathrm{ml} \mathrm{TNF} \alpha$ for various lengths of time in proliferation (C) and differentiation (D) medium, and Ascl2 mRNA expression levels were examined. The results were normalized to NSCs in differentiation medium without TNF $\alpha$ for $5 \mathrm{~h}$. $(\mathrm{n}=3)$. (E-F) NSCs were treated with TNF $\alpha$ of different doses for $48 \mathrm{~h}$ in proliferation $(\mathbf{E})$ and differentiation $(\mathbf{F})$ medium, and the protein levels of ASCL2 were examined. Data in $(\mathbf{A}),(\mathbf{B}),(\mathbf{C})$ and $(\mathbf{D})$ are represented as the means \pm SEM. $* \mathrm{p}<0.05 ; * * \mathrm{p}<0.01$; $* * * \mathrm{p}<0.001$ by one-way analysis of variance. 
A

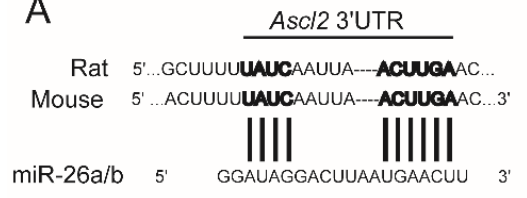

B

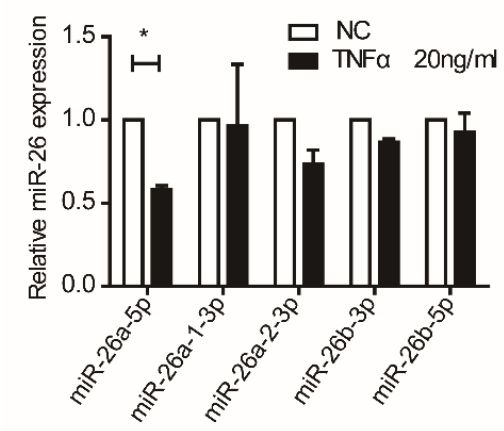

D

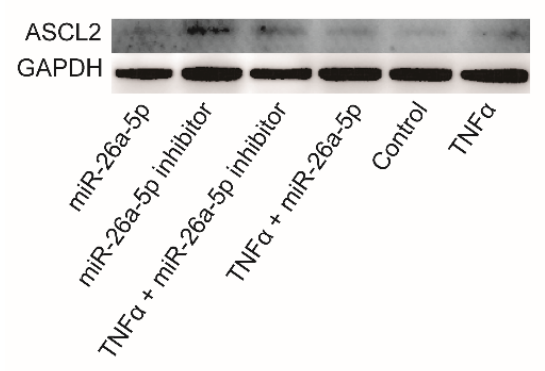

C
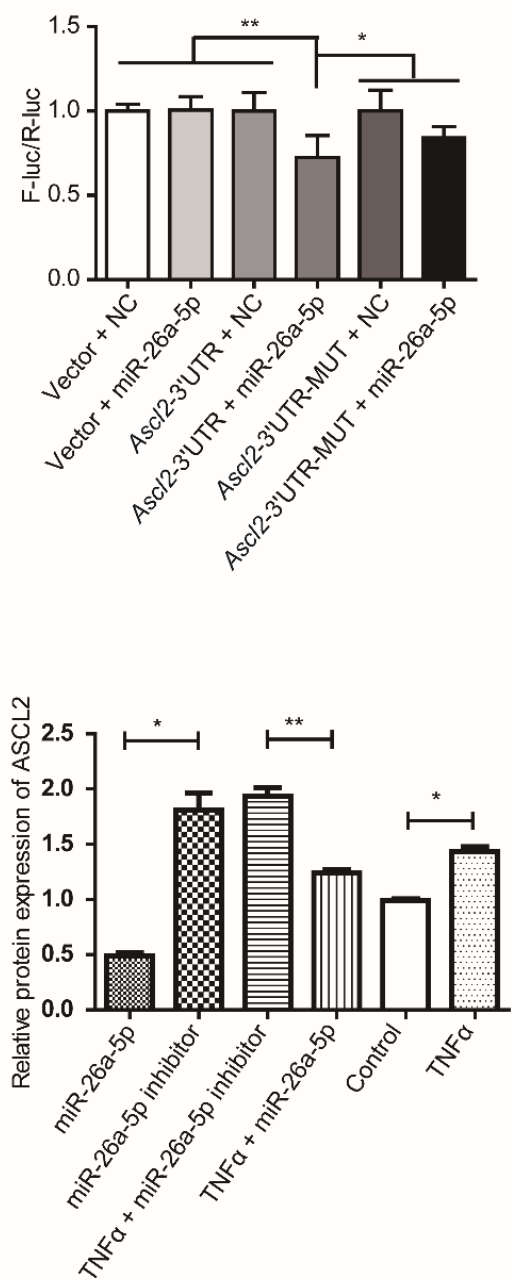

Figure 2. MiR-26a regulates Ascl2 expression. (A) The alignments of 3'UTR of Ascl2 and miR-26a/b as predicted by TargetScan analysis. The sequences show a high level of complementarity (indicated by vertical bars) and sequence conservation between mice and rats. (B) Expression levels of different miR-26 family members following $\mathrm{TNF} \alpha$ treatment for $5 \mathrm{~h}$ in NSCs. The results were normalized to NC. $(n=3)$. (C) NIH3T3 cells were transfected with empty control vectors, Ascl2 3'UTR luciferase construct or Ascl2 3'UTR mutation luciferase construct together with miR-26a-5p mimics. Forty-eight hours following transfection, cells were collected and lysed. Firefly luciferase activities were examined and normalized to Renilla luciferase activities. $\quad(n=6)$. Similar results were obtained in $293 \mathrm{~T}$ cell line as shown in Figure S4C. The results were normalized to vector $+\mathrm{NC}$. (D) NSCs were transfected with miR-26a-5p mimics or miR-26a-5p inhibitor with or without TNF $\alpha$ for $48 \mathrm{~h}$, and ASCL2 protein levels were examined. Control means NSCs culture in proliferation medium without $\mathrm{TNF} \alpha$ or MicroRNA. $(n=3)$. Data in (A), (C) and (D) are represented as the means \pm SEM. ${ }^{*} p<$ $0.05 ; * * \mathrm{p}<0.01 ; * * * \mathrm{p}<0.001$ by Student's $t$ test for comparison (B) and one-way analysis of variance (C) and (D).

\section{RESULTS}

\section{Exposure to TNF $\alpha$ up-regulates Ascl2 expression in neural stem cells.}

Our previous study showed that $\mathrm{TNF} \alpha$ differentially regulates NSCs and neuronal precursors through transcriptional and apoptotic pathways, respectively [2]. To examine the transcriptional changes in stem cellrelated genes downstream of TNF $\alpha$ treatment in murine NSCs, we performed a pathway focused array (GEArray Express Mouse Neurogenesis and Neural Stem Cell Microarray, EMM-404). NSCs of P7 were cultured as monolayer in a differentiation medium for $5 \mathrm{~h}$ with or without $20 \mathrm{ng} / \mathrm{ml} \mathrm{TNF} \alpha$ and/or SN50 (an inhibitor that blocks translocation of NF-kB to nucleus). Two hundred and eighty-one genes related to neural stem cells plus Gapdh as an internal control gene were examined (Supplementary Fig. 1). Among these, 8 genes (Ascl2, Hes6, P21, Nentrin1, JHDM3A, NeuroD, GFAP, Mash1) were chosen for confirmation with quantitative PCR (qPCR, the primer information was listed in Table S1); in addition, cells cultured under a proliferation condition (Neurobasal A, L-glutamine, B-27 without vitamin A, 20 $\mathrm{ng} / \mathrm{ml} \mathrm{FGF-2,} \mathrm{and} 20 \mathrm{ng} / \mathrm{ml} \mathrm{EGF)} \mathrm{for} 5 \mathrm{~h}$ and a differentiation condition (Neurobasal A, L-glutamine, B27 without vitamin A) for $72 \mathrm{~h}$ with or without TNF $\alpha$ were added for the confirmation test (Supplementary Fig. 2). Ascl2 expression increased and Hes6 expression decreased following TNF $\alpha$ treatment, which was partially reversed by SN 50 treatment under the $5 \mathrm{~h}$ differentiation condition (Supplementary Fig. 2A). Under conditions of differentiation for $72 \mathrm{~h}$ or proliferation for $5 \mathrm{~h}, \mathrm{Ascl} 2$ expression also consistently increased and Hes6 decreased with TNF $\alpha$ treatment (Supplementary Fig. 2B and $2 \mathrm{C}) . \mathrm{TNF} \alpha$ treatment up-regulated expression of $p 21$ and Netrin1 (Supplementary Fig. 2). The role of Ascl2 in neural stem cells has largely been unexplored, and therefore we focused this study on this particular gene. 
A

Day 1

Day 2

Day 4

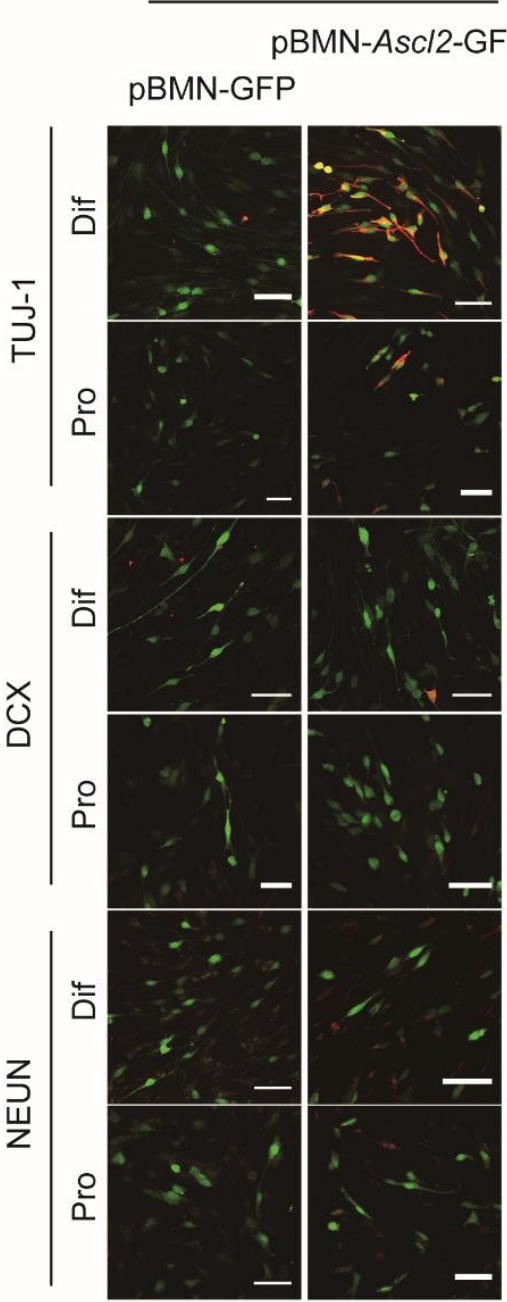

$\frac{\text { pBMN-Asc/2-GFP }}{\text { pBMN-GFP }}$

$\overline{\text { pBMN-Asc/2-GFP }}$

PBMN-GFP

pBMN-GFP
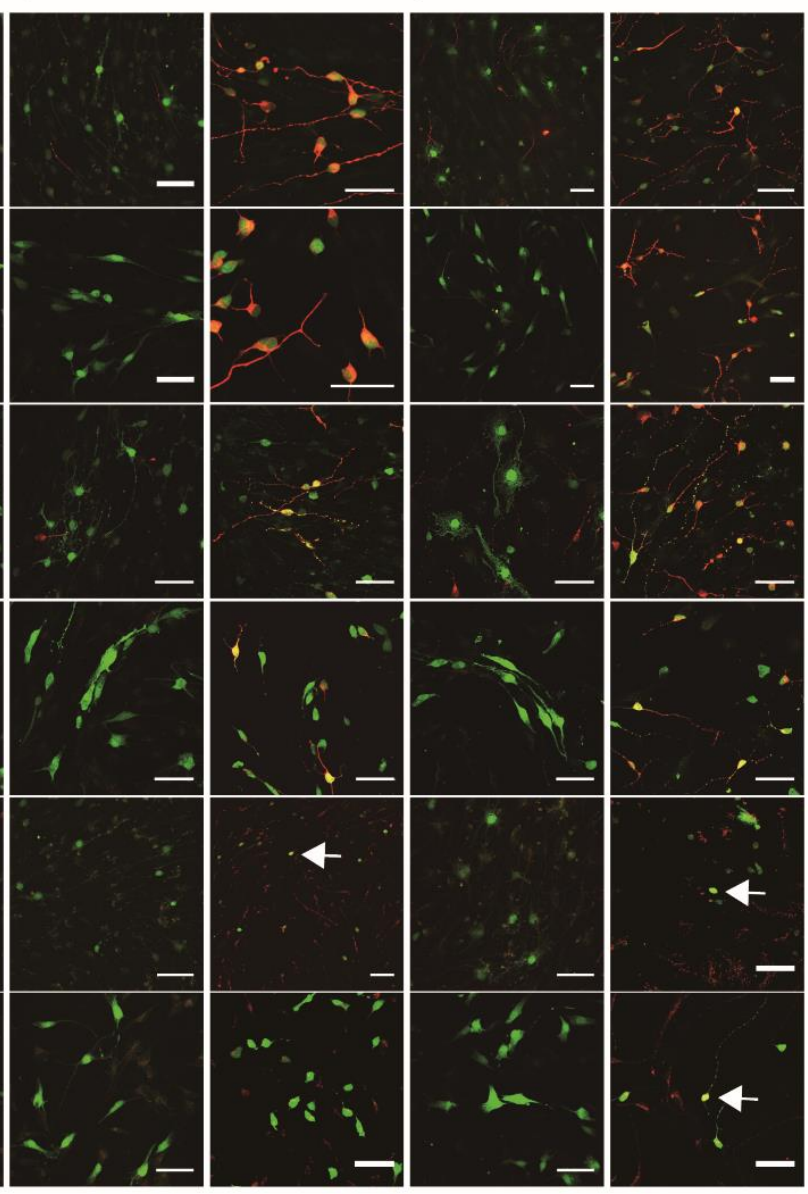

B

C

D

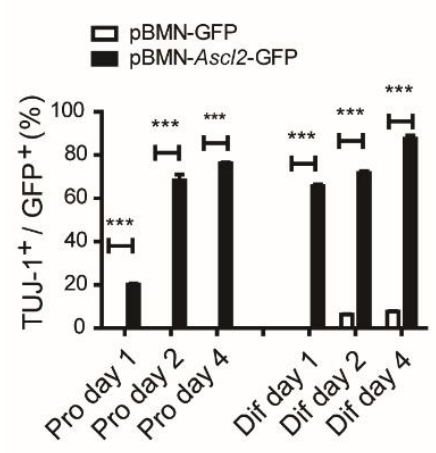

\section{口 $\mathrm{PBMN}-\mathrm{GFP}$ \\ PBMN-Asc/2-GFP}

므 PBMN-GFP

pBMN-Asc/2-GFP
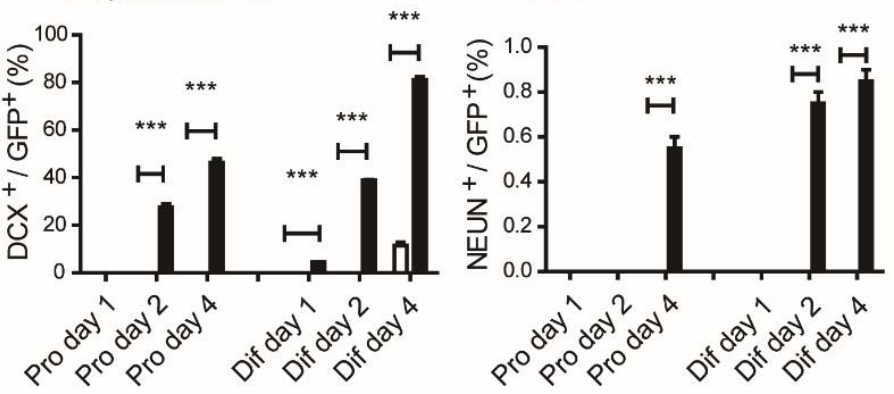

Figure 3. Ascl2 affects the differentiation of NSCs in vitro. (A) Monolayer murine NSCs were infected with retrovirus encoding $\mathrm{pBMN}-A s c l 2-\mathrm{GFP}$ or $\mathrm{pBMN}-\mathrm{GFP}$, which were then subjected to a differentiation or proliferation condition for 1, 2 and 4 days. Early neuronal markers TUJ-1 and DCX, and mature neuron marker NEUN were stained. Pro, proliferation; Dif, differentiation. Scale bars, $50 \mu \mathrm{m}$. (B-D) The proportions of TUJ-1-, DCX- and NEUN-positive cells among $\mathrm{GFP}^{+}$cells were scored. $(\mathrm{n}=10-18)$. Data in (B-D) are represented as the means \pm SEM. ${ }^{*} \mathrm{p}<0.05 ; * * p<0.01 ; * * \mathrm{p}<0.001$ by Student's t test for comparison. 
A
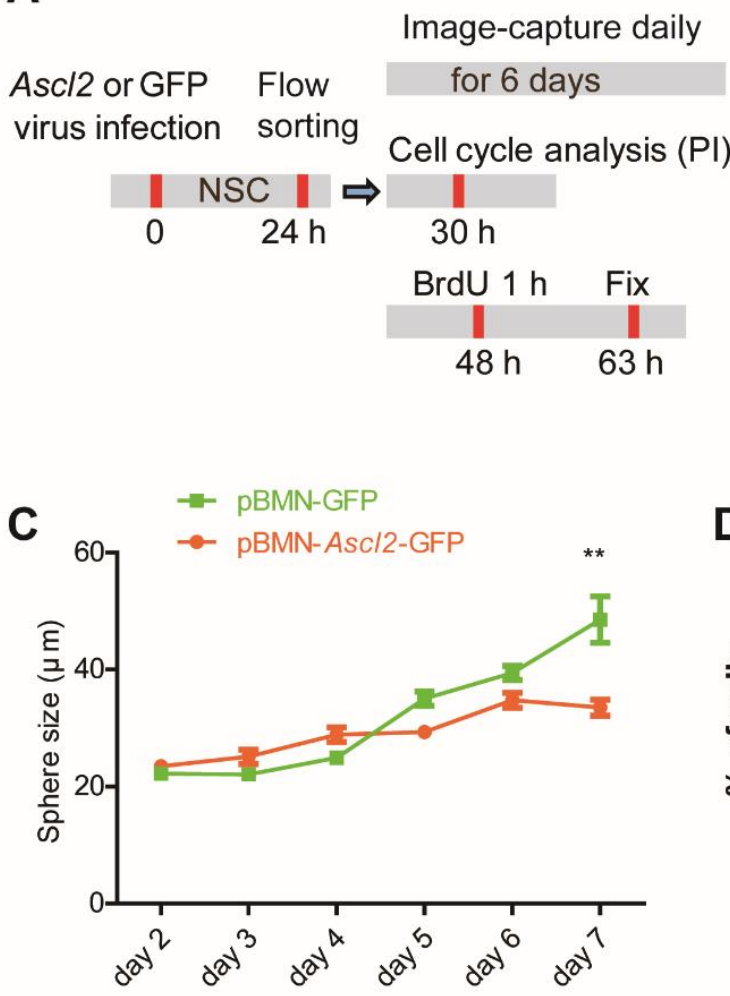

E

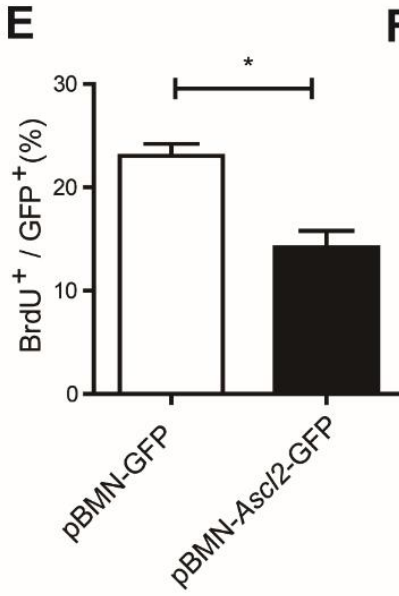

B Bright field
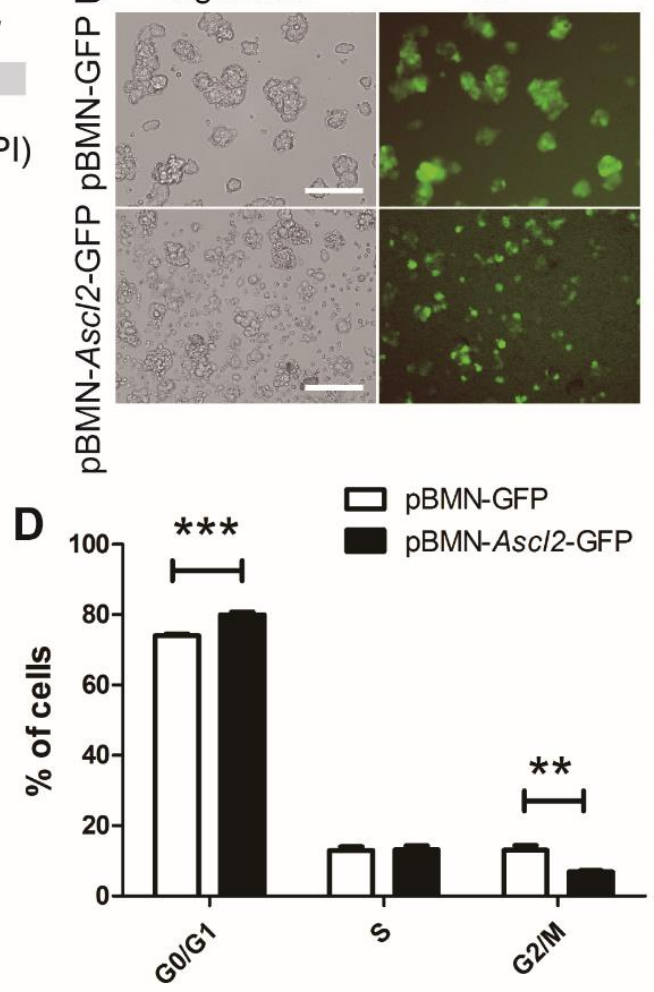

G
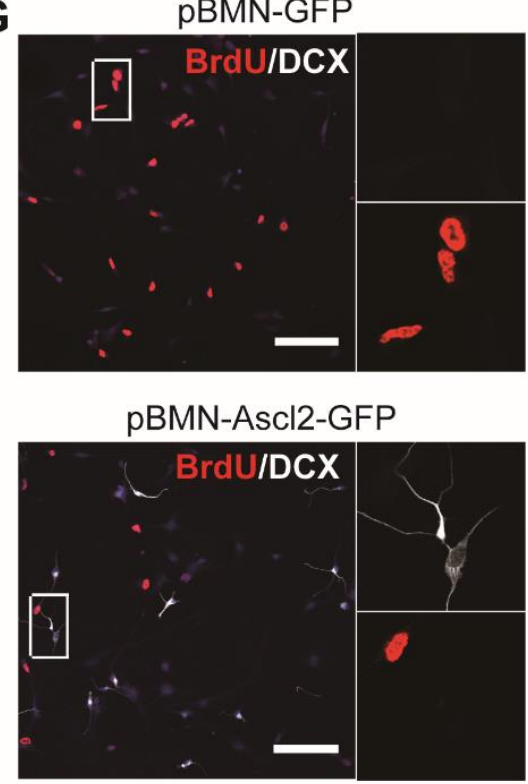

Figure 4. The impact of Ascl2 overexpression on the proliferation of NSCs. (A) Schematic representation of the experimental procedures. (B) The flow cytometer-sorted single cells were cultured in a proliferation medium to test the ability to form neurospheres. Representative pictures 5 days after flow cytometer sorting were shown. (C) The sphere sizes were measured from day 2 through day 7 after flow cytometer sorting. $(\mathrm{n}=17-47)$. (D) Cell cycle progression in proliferation condition was analyzed by PI staining and flow cytometry. ( $\mathrm{n}=3$ ). (E-F) The proliferative capacity was tested by BrdU pulsing for $1 \mathrm{~h}$ and immunostaining 14 $\mathrm{h}$ later. The proportions of $\mathrm{BrdU}^{+}$and $\mathrm{DCX}^{+}$cells among $\mathrm{GFP}^{+}$cells were scored respectively. $(\mathrm{n}=3)$. $(\mathbf{G}) \mathrm{Co}-$ labeling of BrdU with DCX. Scale bars, $100 \mu \mathrm{m}$. Data in (C), (D), (E) and (F) are represented as the means \pm SEM. ${ }^{*} \mathrm{p}<0.05 ;{ }^{* *} \mathrm{p}<0.01 ;{ }^{* * *} \mathrm{p}<0.001$ by Student's $\mathrm{t}$ test for comparison. 
A
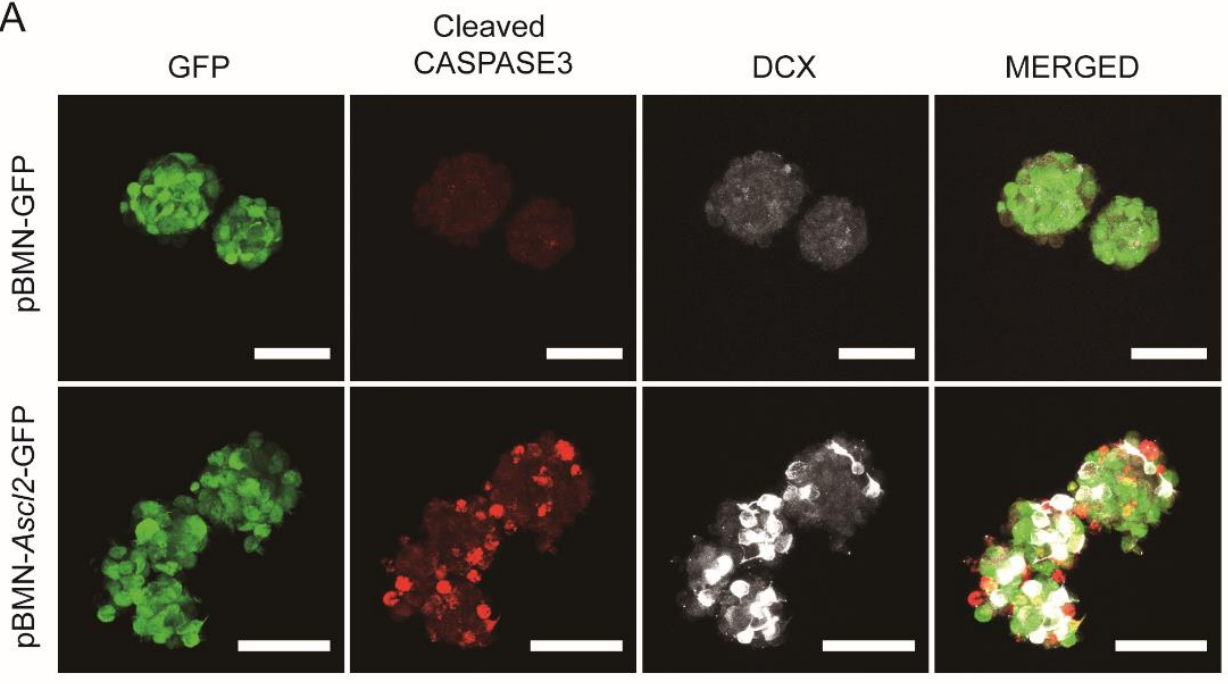

B

C

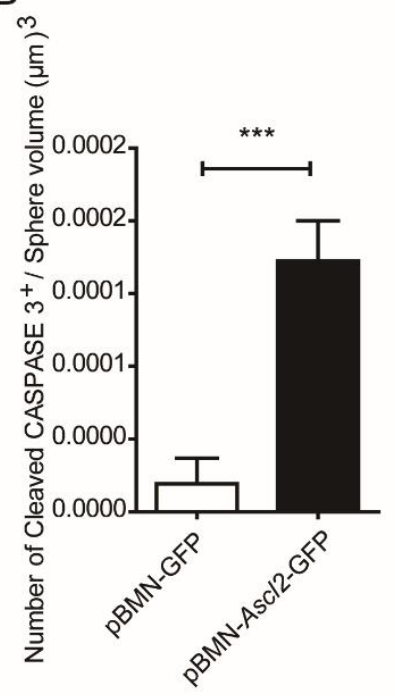

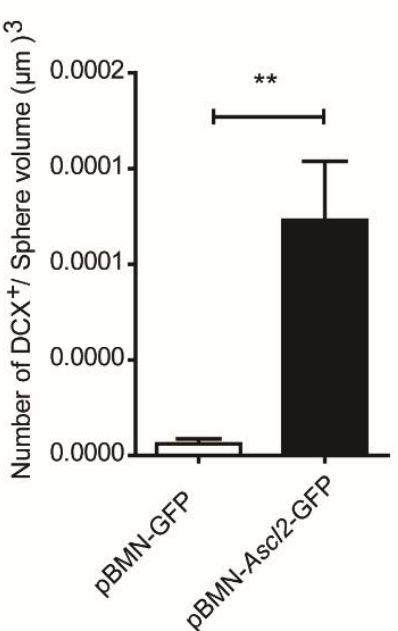

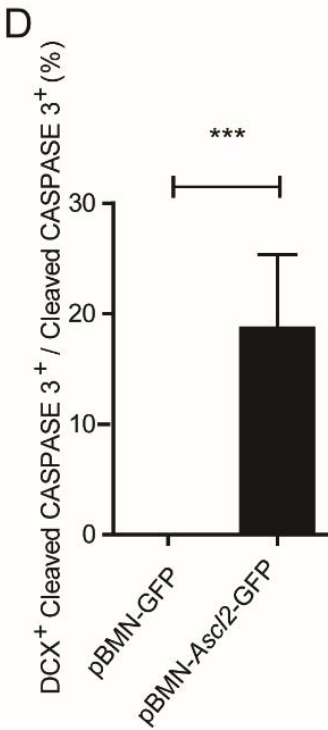

Figure 5. Overexpression of Ascl2 induces expression of cleaved CASPASE 3 in neurospheres. (A) NSCs infected with retrovirus encoding Ascl2 and GFP or GFP only were sorted by using flow cytometry, $24 \mathrm{~h}$ later, the spheres were immunostained for cleaved CASPASE 3 and DCX. Scale bars, $50 \mu \mathrm{m}$. (B-C) The cells positive for cleaved CASPASE 3 and DCX were quantified respectively. ( $n=9-11)$. (D) The proportion of cleaved CASPASE 3-positive cells co-expressing DCX was scored. $(n=9-11)$. Data in (B), (C) and (D) are represented as the means \pm SEM. ${ }^{* *} \mathrm{p}<0.01$; $* * * p<0.001$ by Student's $t$ test for comparison.

We first investigated Ascl2 expression under more thorough conditions that included different doses of TNF $\alpha$ $(0,4,10,20,50$, and $100 \mathrm{ng} / \mathrm{ml})$ for $5,10,24$, and $48 \mathrm{~h}$ either in proliferation or differentiation medium (Fig. 1A and B). Under the proliferation condition, NSCs expressed NSC-specific markers NESTIN and SOX2 (Supplementary Fig. 3A). When NSCs were differentiated for 7 days, mature NEUN+ neurons started to appear, and the proportion of mature neurons continued to increase over time (Supplementary Fig. 3B), proving that the differentiation system worked. Samples from various conditions were run in parallel so that values could be compared between conditions. In general, Ascl 2 mRNA levels were increased with higher concentrations of TNF $\alpha$ treatment for $48 \mathrm{~h}$, both in proliferation and differentiation medium (Fig. 1A and B). Interestingly, Ascl2 expression was higher in differentiation vs. proliferation condition (Fig. 1B). Following treatment of $\mathrm{TNF} \alpha(20 \mathrm{ng} / \mathrm{ml})$ for various lengths of time, Ascl2 levels were increased, with a longer period of exposure to $\mathrm{TNF} \alpha$ generally corresponding to a higher level of Ascl2 (Fig. 1C and D). Along the course of differentiation, Ascl 2 expression was up-regulated over time (Fig. 1D), indicating a possible role in NSC differentiation. Because Ascl2 expression 
increased in the differentiation medium but not in the proliferation medium (without TNF $\alpha$ treatment), TNF $\alpha$ induced up-regulation of Ascl2 was more marked in proliferation medium vs. in differentiation medium (Fig. $1 \mathrm{C}$ and D). The protein levels of ASCL2 as examined by using Western blot were enhanced by TNF $\alpha$ treatment in a dose-dependent manner (Fig. 1E and F).

\section{Mir-26a may mediate regulation of Ascl2.}

Two receptors of TNF $\alpha$ exist - TNFR1 and TNFR2, which play different, sometimes even opposing roles in a context-dependent manner [2]. We used NSCs isolated from TNFR $1^{--}$and TNFR2 $2^{--}$mice to determine whether TNFR 1 or TNFR 2 was involved in regulation of $A s c l 2$ by $\mathrm{TNF} \alpha$. In TNFR $1^{-/-} \mathrm{NSCs}$, the effect of TNF $\alpha$ on Ascl 2 was abolished, suggesting that TNFR1, but not TNFR2, mediates the effect (Supplementary Fig. 4A).

Next, we tested whether TNFa regulates Ascl2 through transcriptional activation. The promoter region of Ascl2 from -968 to +444 bp relative to the transcription start site (TSS) was cloned into pGL3 vector to drive the downstream luciferase gene expression. A web-based software (LASAGNA-Search 2.0) predicted a possible NF-kB binding site with a score of 79.7 at -310 bp relative to TSS (Supplementary Fig. 5). Murine NSCs cultured as monolayer were transfected with pGL3-Ascl2 promoter together with Renilla control vectors. The next day the cells were treated with TNF $\alpha$ and/or SN50 for 5 or $24 \mathrm{~h}$. Twenty-four hours after treatment, the cells were lysed for dual luciferase assay. The results showed that TNF $\alpha$ pathway did not regulate Ascl2 by transcriptional activation of the tested promotor region (Supplementary Fig. 4B).

By using the software TargetScan, it was predicted that miR-26 may target the 3' untranslated region (UTR) of Ascl2 (Fig. 2A). Wei et al. showed that NF-kB pathway down-regulates miR-26a in cardiac fibrosis [15]. NF-kB pathway is activated in NSCs following TNF $\alpha$ treatment [2], which was also confirmed in the current study (Supplementary Fig. 3C). We therefore hypothesized that TNF $\alpha$ might regulate Ascl 2 expression through miR-26a. To test this hypothesis, we first examined whether TNF $\alpha$ treatment could reduce miR-26a expression in NSCs. NSCs were cultured as monolayer and treated with or without TNF $\alpha$ for $5 \mathrm{~h}$, and different miR-26 family members (mmu-miR-26a-5p, mmu-miR-26a-1-3p, mmumiR-26a-2-3p, mmu-miR-26b-5p, mmu-miR-26b-3p) were examined (Fig. 2B). Among them, only miR-26a-5p was significantly down-regulated. Next, we cloned the 3'UTR of Ascl2 to replace the 3'UTR of luciferase gene in a pGL3-Luc vector, and tested whether miR-26a-5p could affect luciferase expression in a NIH3T3 system (Fig. 2C) and 293T (Supplementary Fig. 4C). In both systems, delivery of miR-26a-5p into cells by using a Lipofectamine ${ }^{\circledR}$ RNAiMAX could significantly reduce luciferase activity (normalized by Renilla in a dual luciferase system), suggesting that miR-26a might directly target the 3'UTR of Ascl2 and down-regulate its expression. To confirm this possibility, we delivered miR26a mimic (5'UUCAAGUAAUCCAGG AUAGGCU3') and its inhibitor (5'AGCCUAUCC UGGAUUACUUGAA3') into NSCs with or without TNF $\alpha$, and then examined ASCL2 protein expression by using Western blot. MiR-26a-5p but not its inhibitor significantly decreased the protein levels of Ascl2 following TNF $\alpha$ treatment (Fig. 2D).

\section{Ascl2 affects the differentiation and proliferation of NSCs in vitro.}

To investigate the role of Ascl2 in NSCs, retrovirus encoding Ascl2 and GFP (pBMN-Ascl2-GFP) or GFP only (pBMN-GFP) as controls were used to infect monolayer murine NSCs, which were then subjected to a differentiation or proliferation scheme. The infection rate was about $15 \%$, and the green cells were selected for analysis (Fig. 3A). Early neuronal markers TUJ-1 and DCX, and mature neuron maker NEUN were stained and scored among the $\mathrm{GFP}^{+}$cells. In the proliferation condition, few TUJ $-1^{+}$or $\mathrm{DCX}^{+}$neuronal precursors were observed in the control group infected with GFP virus only at any time points tested (Fig. 3A). In contrast, infected cells overexpressing Ascl2 showed a premature neuronal differentiation even in the proliferation condition. On day 1 , there were already $20.1 \pm 0.37 \%$ $\mathrm{TUJ}-1^{+}$cells among the green cells; and on day 4 , about $74.8 \pm 1.26 \%$ TUJ- $1^{+}$cells and $45.8 \pm 1.38 \% \mathrm{DCX}^{+}$cells were detected in the proliferation condition (Fig. 3A-C). In the differentiation condition, the percentages of TUJ-1 ${ }^{+}$ and $\mathrm{DCX}^{+}$cells in control group gradually increased and reached about $10 \%$ on day 4 (Fig. 3A-C). In the Ascl2overexpressing group, two days of differentiation already led to more than $70 \%$ of TUJ- $1^{+}$and around $40 \%$ of $\mathrm{DCX}^{+}$ cells; on day 4 , the proportion increased to more than $80 \%$ for $\mathrm{TUJ}^{+} 1^{+}$and $\mathrm{DCX}^{+}$cells (Fig. 3B and C), > 8-fold higher than that in control group. As to mature neuronal marker NEUN, no positive cells were observed in control groups in any of the conditions tested. It normally took 7 days for the $\mathrm{NEUN}^{+}$mature neurons to appear in the control group under the current experiment setting (Supplementary Fig. 3B). But in the Ascl2-overexpressing group, there were about $0.6 \%$ and $0.9 \% \mathrm{NEUN}^{+}$cells detected among the green cells on day 4 of proliferation and differentiation, respectively (Fig. 3D). The results suggested that $A s c l 2$ expression resulted in a premature neuronal differentiation of NSCs. 
Next, we examined the impact of Ascl2 on the proliferation aspect of NSCs. NSCs infected with retrovirus encoding Ascl 2 and GFP or GFP only were sorted by using flow cytometer, and the $\mathrm{GFP}^{+}$cells were subjected to sphere culture, cell cycle analysis, and BrdU pulse experiments (Fig. 4A). The single cells sorted by flow cytometer were cultured in a proliferation medium to test the ability to form neurospheres (Fig. 4B and C). On day 5, Ascl2-expressing spheres looked ragged on surface, compared with control cells (Fig. 4B). The sphere sizes were quantified from day 2 through day 7, and Ascl2 spheres were significantly reduced in size from day 7 (Fig.
4C). The cell cycle progression in the proliferation condition was analyzed by PI staining of the nuclear content. Ascl2-expressing NSCs showed a prolonged G0/G1 phase and reduced G2/M phase (Fig. 4D). The proliferative capacity was also tested by BrdU pulsing for $1 \mathrm{~h}$ and immunostaining $14 \mathrm{~h}$ later. The proportion of $\mathrm{BrdU}^{+}$cells was significantly lower in Ascl2-expressing group vs. control group (Fig. 4E and $\mathrm{G}$ ), in agreement with an enhanced percentage of $\mathrm{DCX}^{+}$cells (Fig. 4F and G).
A

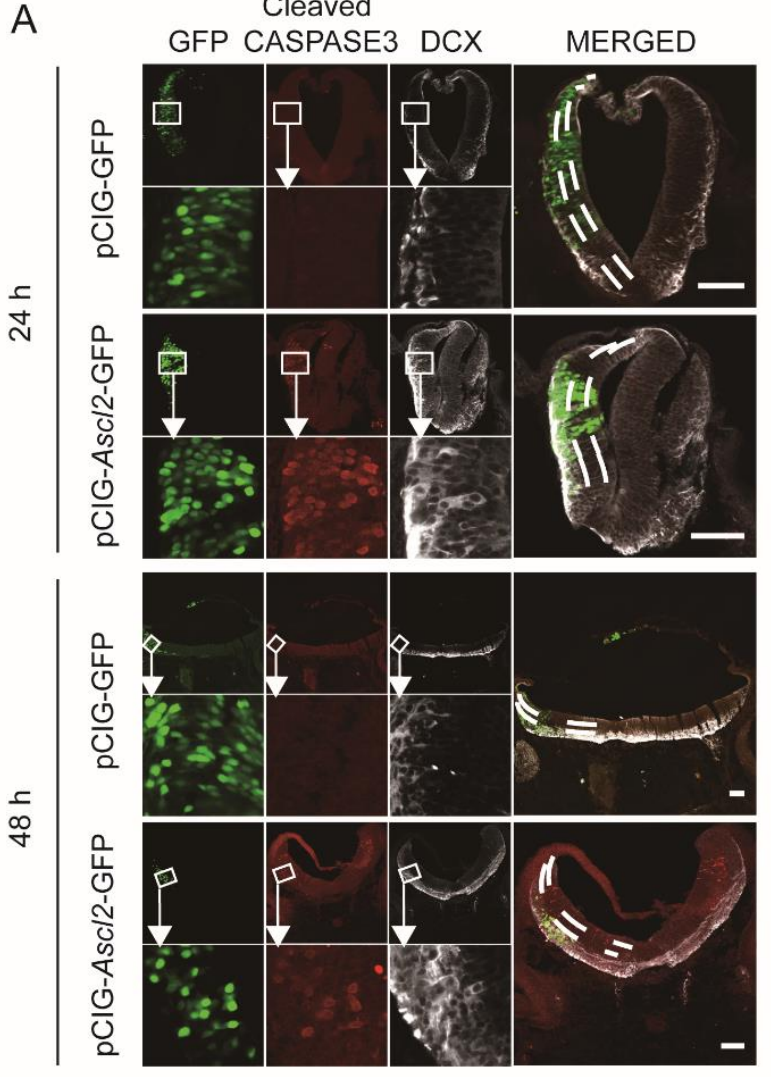

D

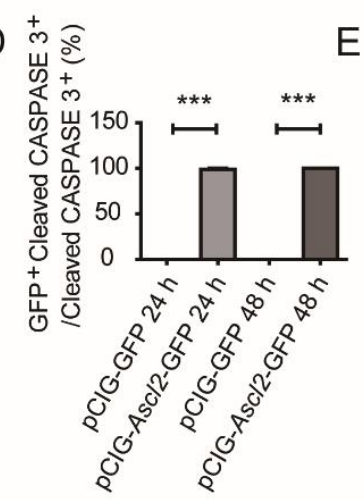

$E_{m}^{+}$

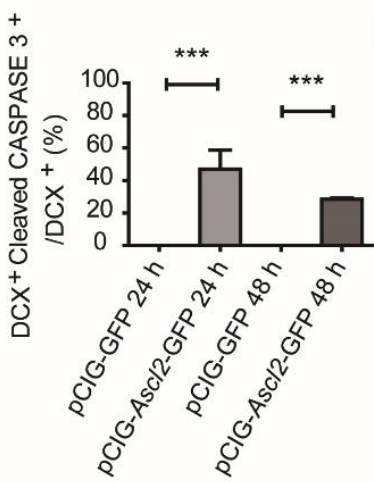

$\mathrm{B}$ ช

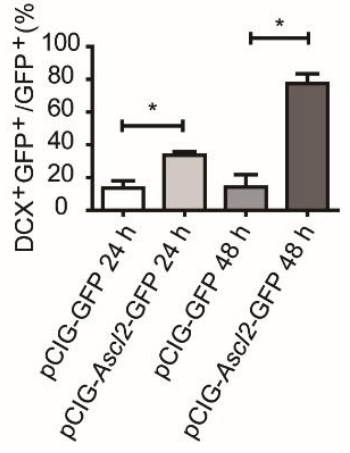

C +
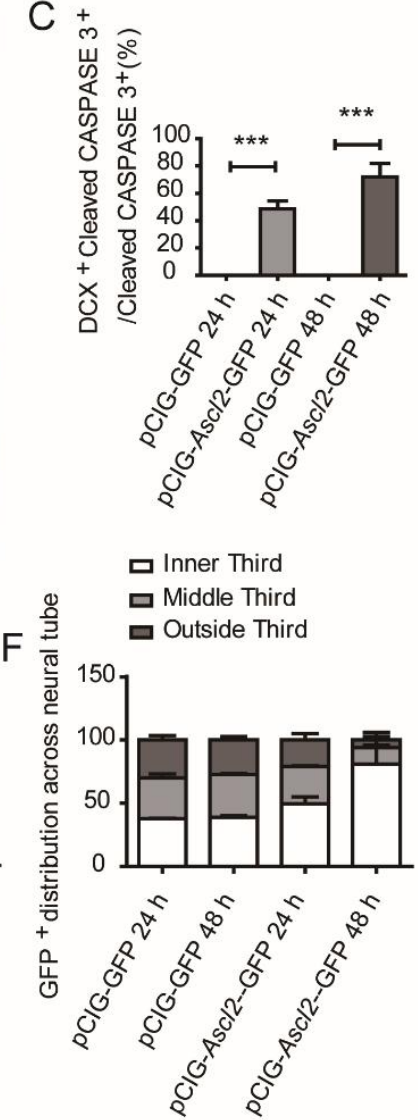

Figure 6. Overexpression of Ascl2 induces expression of cleaved CASPASE 3 in ovo. (A) PCIG-Ascl2-GFP vectors and the control vectors pCIG-GFP were electroporated into chicken embryo neural tubes, $24 \mathrm{~h}$ and $48 \mathrm{~h}$ later, the chicken embryos were fixed and sliced for staining of cleaved CASPASE 3 and DCX. Scale bars, $200 \mu \mathrm{m}$. (B) The proportions of $\mathrm{GFP}^{+}$cells coexpressing DCX were scored $24 \mathrm{~h}$ and $48 \mathrm{~h}$ after electroporation. $(n=6)$. (C) The proportions of cleaved CASPASE3-positive cells co-expressing DCX were scored $24 \mathrm{~h}$ and $48 \mathrm{~h}$ after electroporation. $(\mathrm{n}=6)$. (D) The proportions of cleaved CASPASE3-positive cells that were GFP-positive were scored $24 \mathrm{~h}$ and $48 \mathrm{~h}$ after electroporation. $(\mathrm{n}=6)$. (E) The proportions of DCX-positive cells that co-expressed cleaved CASPASE3 were scored $24 \mathrm{~h}$ and $48 \mathrm{~h}$ after electroporation. $(\mathrm{n}=6)$. (F) Distribution of $\mathrm{GFP}^{+}$cells in the neural tubes. $(n=6)$. Data in (B), (C), (D) and (E) are represented as the means \pm SEM. $* \mathrm{p}<0.05 ; * * \mathrm{p}$ $<0.01 ; * * \mathrm{p}<0.001$. 


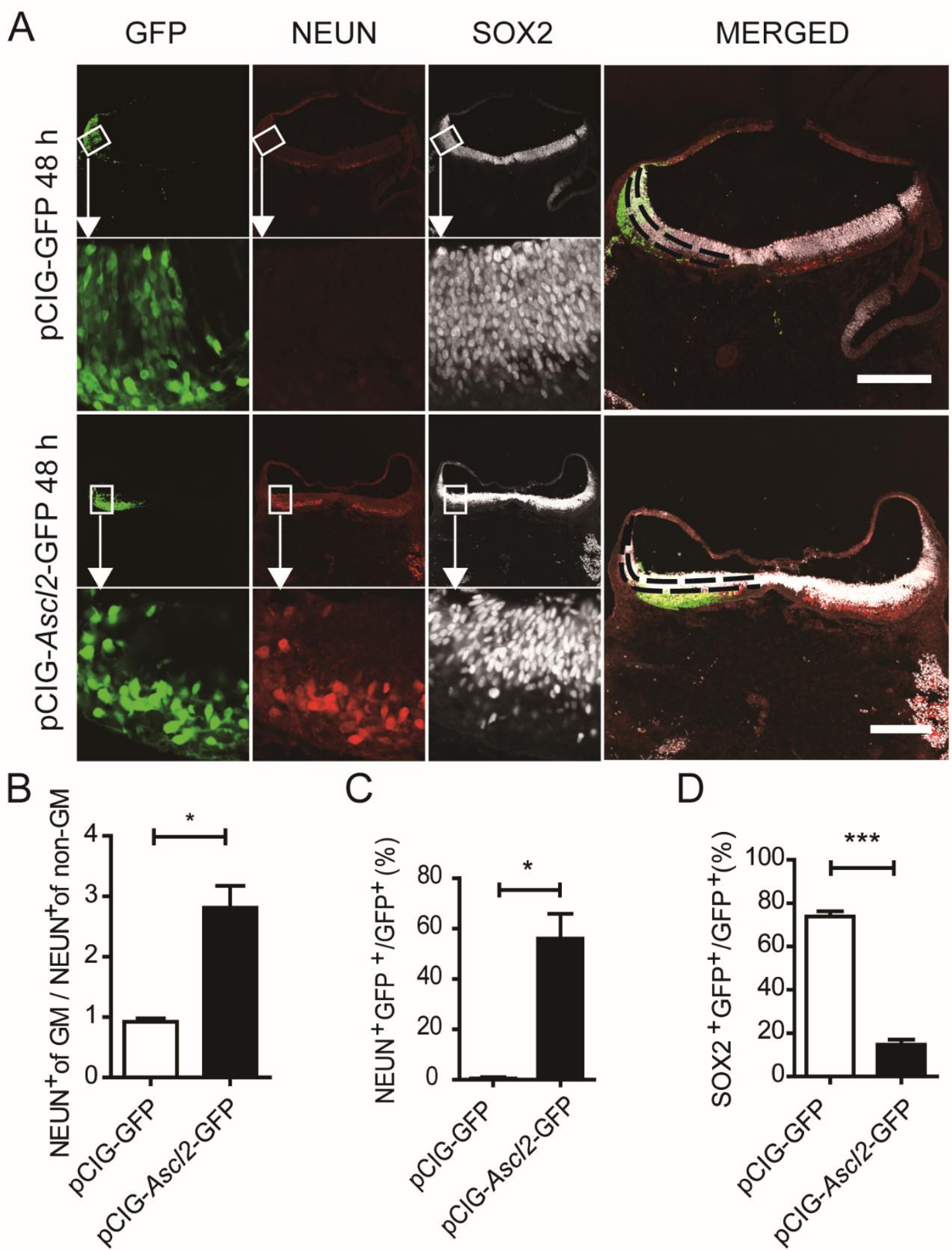

Figure 7. The impact of Ascl2 overexpression on differentiation in ovo. Related to Figure S6. (A) Expression of neural stem cell marker SOX2 and mature neuron marker NEUN at $48 \mathrm{~h}$ post-electroporation. (B) Rate of NEUN-positive cells of genetically modified (GM) side over non-genetically modified (non-GM) side $48 \mathrm{~h}$ post-electroporation. $(\mathrm{n}=6)$ ). (C) The proportion of NEUN- and GFP-double positive cells in $\mathrm{GFP}^{+}$cells $48 \mathrm{~h}$ post-electroporation. (n=6). (D) The proportion of SOX2- and GFP-double positive cells in $\mathrm{GFP}^{+}$cells $48 \mathrm{~h}$ post-electroporation. ( $\left.\mathrm{n}=6\right)$. Data in (B), (C) and (D) are represented as the means \pm SEM. ${ }^{*} \mathrm{p}<0.05 ; * \mathrm{*}<0.01 ; * * \mathrm{p}<0.001$ by Student's $\mathrm{t}$ test for comparison. 
We also examined the expression of cleaved CASPASE 3 with or without exogenous Ascl2 expression (Fig. 5). Ascl2-expressing NSCs cultured in a proliferation medium showed a much higher proportion of cleaved CASPASE $3^{+}$cells, and among them, about 18.7 $\%$ were DCX-positive (Fig. 5). Fernando et al. has shown that expression of active CASPASE 3 can be a conserved feature of neuronal differentiation in non-apoptotic cells [16]. The higher expression of cleaved CASPASE 3 may be a result from Ascl2-induced neuronal differentiation per se, and/or from an increased level of apoptosis. Further investigation is needed to address this issue.

The in vitro data showed that Ascl2-expression led to a premature neuronal differentiation, reduced proliferation, and increased expression of cleaved CASPASE 3 in NSCs.

\section{In ovo electroporation of Ascl2 leads to early neuronal differentiation.}

Next, we examined the function of Ascl2 in ovo. pCIGAscl2-GFP plasmid and control construct pCIG-GFP were injected into neural tubes of Hamburger-Hamilton $(\mathrm{HH})$ stage 10 chicken embryos, followed by application of electric field for 50 milliseconds at 18 volts. The negatively charged vectors migrated toward the positively charged electrode positioned at one side of the developing neural tube, and the other side was used as an internal control (Supplementary Fig. 6A). Twenty-four or $48 \mathrm{~h}$ later, the chicken embryos were fixed and sliced for staining to characterize neuronal differentiation.

In the developing neural tubes, neural stem cells are localized more at the lumen side and neuronal precursors and mature neurons more at the outside edges (Figs. 6 and 7). The horizontal sections of neural tubes were arbitrarily divided into 3 equal parts for analysis on the vector side. At $24 \mathrm{~h}$ post-electroporation, the $\mathrm{GFP}^{+}$cells were distributed across the 3 arbitrary sections by $37.9 \pm 0.3 \%$ (outside third), $32.2 \pm 2.2 \%$ (middle third), and $30.0 \pm 2.4$ $\%$ (inner third), in the control vector group. The distribution of $\mathrm{GFP}^{+}$cells across the 3 arbitrary sections were $49.5 \pm 3.9 \%$ (outside third), $29.5 \pm 0.4 \%$ (middle third), and $21.0 \pm 3.6 \%$ (inner third), in the pCIG-Ascl2 group (Fig. 6A and F); at $48 \mathrm{~h}$, the $\mathrm{GFP}^{+}$cells were distributed by $38.9 \pm 1.0 \%$ (outer third), $33.6 \pm 0.8 \%$ (middle third), and $27.5 \pm 1.8 \%$ (inner third), in the control vector group. The $\mathrm{GFP}^{+}$cells were distributed by $80.8 \pm 10.5 \%$ (outer third), $13.1 \pm 6.2 \%$ (middle third), and $6.1 \pm 4.3 \%$ (inner third), in the pCIG-Ascl2 group (Fig. 6A and F). From 24 to $48 \mathrm{~h}$, the proportion of $\mathrm{DCX}^{+}$ cells among the $\mathrm{GFP}^{+}$cells changed from $13.6 \pm 3.1 \%$ to $14.1 \pm 5.4 \%$ in the control vector group, and the proportion increased from $33.7 \pm 1.6 \%$ to $77.4 \pm 4.2 \%$ in the pCIG-Ascl2 group (Fig. 6A and B). The $\mathrm{DCX}^{+}$cells were mostly observed in the outer third section, suggesting that neural stem cells commit to a neuronal fate during or after migration towards the outside edge of neural tubes. At both 24 and $48 \mathrm{~h}$, pCIG-Ascl 2 groups showed markedly higher proportions of $\mathrm{DCX}^{+}$neuronal precursor cells, compared with those of pCIG-GFP control groups (Fig. 6B), suggesting that Ascl2 had promoted neuronal differentiation of NSCs in ovo.

In control vector groups, either at 24 or $48 \mathrm{~h}$ postelectroporation, almost no cleaved CASPASE $3^{+}$cells were detected; in contrast, CASPASE $3^{+}$cells were observed in pCIG-Ascl2 groups (Fig. 6A, C, D and E). Almost all the CASPASE $3^{+}$cells detected were Ascl2transfected cells (Fig. 6A and D). About $48.5 \%$ and 72.1 $\%$ of the CASPASE $3^{+}$cells were $\mathrm{DCX}^{+}\left(\mathrm{DCX}^{+} / \mathrm{Casp}^{+}\right)$ at 24 and $48 \mathrm{~h}$, respectively (Fig. 6A and C). Among the $\mathrm{DCX}^{+}$cells, about $47.1 \%$ and $24.3 \%$ were positive for cleaved CASPASE 3 at 24 and $48 \mathrm{~h}$, respectively (Fig. 6A and $\mathrm{E})$.

We also examined neural stem cell marker SOX2 and mature neuron marker NEUN at $48 \mathrm{~h}$ post-electroporation (Fig. 7A). Compared to the opposite side of the neural tube without vector transfection, the number of NEUN ${ }^{+}$ neurons was $2.8 \pm 0.16$ fold higher in the pCIG-Ascl2GFP vector side (Fig. 7B). The proportion of $\mathrm{NEUN}^{+}$in the electroporated $\mathrm{GFP}^{+}$cells were $56.1 \pm 10.0 \%$ in the Ascl 2 group vs. $0.5 \pm 0.4 \%$ in the control vector group (Fig. 7C). Among the $\mathrm{GFP}^{+}$electroporated cells, $14.7 \pm$ $2.3 \%$ were $\mathrm{SOX}_{2}{ }^{+}$in $\mathrm{Ascl} 2$ group vs. $73.8 \pm 1.7 \%$ in control vector group (Fig. 7D); similar results were obtained about the proportion of another mature neuron marker MAP2 as shown in Figure S6B, C and D.

The above data suggest that Ascl2 over-expression can shrink the pool of neural stem cells by inducing premature neuronal differentiation.

\section{DISCUSSION}

In this study, we found that $A s c l 2$ expression is induced in NSCs following treatment with pro-inflammatory cytokine TNF $\alpha$; up-regulation of $A s c l 2$ may be mediated by miR-26a, which targets the 3 ' untranslated region of Ascl 2 mRNA and can be down-regulated by TNF $\alpha$ treatment. Overexpression of Ascl2 inhibits the proliferation, and promotes neuronal differentiation of NSCs, as observed in the in vitro and in ovo experiments.

The way NSCs respond to inflammation may be context-dependent $[1,2]$. Acutely activated microglia, or their conditioned medium, reduces neural progenitor cell survival and prevented neuronal differentiation; whereas chronically activated microglia are permissive to neuronal differentiation [17]. In a context of intracerebral 
transplantation of allogeneic NSCs in mice, allogeneityinduced inflammatory responses reduce neurogenesis [1]. One of the key pro-inflammatory cytokines in the CNS is $\mathrm{TNF} \alpha$. We have shown that TNF $\alpha$ treatment mainly induces apoptotic pathway in neuronal precursor cells and activates NF-kB pathway in NSCs [2]; yet the detailed molecular mechanisms underlying the effects of TNF $\alpha$ on NSCs at the transcriptional level have not been fully depicted. Through a focused pathway array, we identified Ascl2 as a downstream transcription factor that was upregulated in murine NSCs following TNF $\alpha$ treatment. Ascl2 expression is normally very low or at an undetectable level in tissues/cells others than placenta, Schwann cells, and intestine. Upon exposure to TNF $\alpha$, the level of $A s c l 2$ rapidly increased, suggesting that $A s c l 2$ may be an instantaneous mediator in NSCs in response to $\mathrm{TNF} \alpha$, a cytokine often induced by inflammatory challenges. When NSCs were infected with lentivirus encoding control vectors, Ascl2 levels also increased (Supplementary Fig. 4D). Virus infection represents a kind of cellular stress. It is possible that cellular stressors, such as inflammation and virus infection, might lead to up-regulation of acute responders like Ascl2, and trigger an attempt for NSCs to deal with the exogenous changes/challenges. Ascl2-induced neuronal differentiation may reflect such an abortive attempt for NSCs to repair CNS damage by producing more neurons. In Drosophila, transient activity of Scute induces intestine stem cells to produce a pair of enteroendocrine cells [10], in agreement with what we found in the current study that Ascl2 participates in stem cell differentiation.

In many neurological disorders/indications, acute inflammatory responses are often considered to play a collectively positive role, facilitating the removal of debris and regeneration of the CNS. However, chronic inflammation is generally regarded as aberrant regulation of the immune system that contributes to certain pathological features of the diseases. In the current study, overexpression of Ascl2 in the in vitro and in ovo experiments may mimic the chronic/long term inflammatory condition. In these experimental settings, Ascl2 inhibits NSC proliferation, and induces premature neuronal differentiation. The net results are the reduction of neural stem cell pool and decrease in neurogenesis. Whether Ascl2 is the major mediator in conditions where chronic inflammation inhibits neurogenesis requires further investigation.

Interestingly, Ascl2 seems to play different, even seemingly opposing roles in different tissues and species. In mouse intestine, Ascl2 helps to maintain the stem cell signature of intestine stem cells; in mouse placenta, Ascl2 participates in the differentiation to spongiotrophoblast cells. In Drosophila midgut, scute instructs the asymmetric division of intestine stem cells, as well as induces exactly one-time proliferation of enteroendocrine progenitor cells and generation of one pair of enteroendocrine cells. In mouse intestine stem cells, Ascl2 is the direct target of Wnt signaling; whereas in mouse epidermis, Ascl 2 is regulated by Notch signaling pathway. In Drosophila gut, Ascl 2 forms a self-activating regulatory loop. The context-dependent function/ regulation of $A s c l 2$ indicates that $A s c l 2$ may work with different co-factors under different conditions. Ascl2 can form dimers with nuclear B-cateninand TCFs [18, 19]. Binding of Ascl2 to E-box (CANNTG) can be antagonized by another transcription factor HAND1 [20]. In NSCs, whether and how Ascl2 interacts with other cofactors is still unclear and warrants further study.

In short, Ascl2 may serve in NSCs as a standby factor in normal conditions. Upon TNF $\alpha$ exposure, Ascl2 in NSCs readily responds and promotes neuronal differentiation of NSCs. Overexpression of Ascl2 also affects the proliferation of NSCs. In chronic inflammation in which TNF $\alpha$ is consistently up-regulated, sustained expression of Ascl2 may inhibit neurogenesis as a net consequence.

\section{Conflict of interest}

The authors declare no competing financial interests.

\section{Acknowledgements}

The work was supported by the following grants. Stem Cell and Translation National Key Project (2016YFA0101403), National Basic Research Program of China (2011CB965103), National Natural Science Foundation of China (81661130160, 81422014, 81561138004), Beijing Municipal Natural Science Foundation (5142005), Beijing Talents Foundation (2017000021223TD03), Support Project of High-level Teachers in Beijing Municipal Universities in the Period of 13th Five-year Plan (CIT \& TCD20180333), Beijing Medical System High Level Talent Award (2015-3-063), Beijing Municipal Administration of Hospitals Clinical Medicine Development of Special Funding Support (ZYLX201706), and the Royal Society-Newton Advanced Fellowship (NA150482).

\section{Supplementary Materials}

The Supplemenantry data can be found online at: www.aginganddisease.org/EN/10.14336/AD.2018.1028.

\section{References}

[1] Chen Z, Phillips LK, Gould E, Campisi J, Lee SW, Ormerod BK, et al. (2011). MHC mismatch inhibits neurogenesis and neuron maturation in stem cell 
allografts. PLoS One, 6:e14787.

[2] Chen Z, Palmer TD (2013). Differential roles of TNFR1 and TNFR2 signaling in adult hippocampal neurogenesis. Brain Behav Immun, 30:45-53.

[3] Guillemot F, Caspary T, Tilghman SM, Copeland NG, Gilbert DJ, Jenkins NA, et al. (1995). Genomic imprinting of Mash2, a mouse gene required for trophoblast development. Nat Genet, 9:235-242.

[4] Kury P, Greiner-Petter R, Cornely C, Jurgens T, Muller HW (2002). Mammalian achaete scute homolog 2 is expressed in the adult sciatic nerve and regulates the expression of Krox24, Mob-1, CXCR4, and p57kip2 in Schwann cells. J Neurosci, 22:7586-7595.

[5] Van der Flier LG, van Gijn ME, Hatzis P, Kujala P, Haegebarth A, Stange DE, et al. (2009). Transcription factor achaete scute-like 2 controls intestinal stem cell fate. Cell, 136:903-912.

[6] Oh-McGinnis R, Bogutz AB, Lefebvre L (2011). Partial loss of Ascl2 function affects all three layers of the mature placenta and causes intrauterine growth restriction. Dev Biol, 351:277-286.

[7] Reed KR, Tunster SJ, Young M, Carrico A, John RM, Clarke AR (2012). Entopic overexpression of Ascl2 does not accelerate tumourigenesis in ApcMin mice. Gut, 61:1435-1438.

[8] Jubb AM, Chalasani S, Frantz GD, Smits R, Grabsch HI, Kavi V, et al. (2006). Achaete-scute like 2 (ascl2) is a target of Wnt signalling and is upregulated in intestinal neoplasia. Oncogene, 25:3445-3457.

[9] Stange DE, Engel F, Longerich T, Koo BK, Koch M, Delhomme N, et al. (2010). Expression of an ASCL2 related stem cell signature and IGF2 in colorectal cancer liver metastases with $11 \mathrm{p} 15.5$ gain. Gut, 59:1236-1244.

[10] Chen J, Xu N, Wang C, Huang P, Huang H, Jin Z, et al. (2018). Transient Scute activation via a selfstimulatory loop directs enteroendocrine cell pair specification from self-renewing intestinal stem cells. Nat Cell Biol, 20:152-161.

[11] Wang S, Wang B, Pan N, Fu L, Wang C, Song G, et al.
(2015). Differentiation of human induced pluripotent stem cells to mature functional Purkinje neurons. Sci Rep, 5:9232.

[12] Farley EK (2013). Gene transfer in developing chick embryos: in ovo electroporation. Methods Mol Biol, 1018:141-150.

[13] Blank MC, Chizhikov V, Millen KJ (2007). In ovo electroporations of $\mathrm{HH}$ stage 10 chicken embryos. J Vis Exp:408.

[14] Li P, Li M, Tang X, Wang S, Zhang YA, Chen Z (2016). Accelerated generation of oligodendrocyte progenitor cells from human induced pluripotent stem cells by forced expression of Sox10 and Olig2. Sci China Life Sci, 59:1131-1138.

[15] Wei C, Kim IK, Kumar S, Jayasinghe S, Hong N, Castoldi G, et al. (2013). NF-kappaB mediated miR26a regulation in cardiac fibrosis. J Cell Physiol, 228:1433-1442.

[16] Fernando P, Brunette S, Megeney LA (2005). Neural stem cell differentiation is dependent upon endogenous caspase 3 activity. FASEB J, 19:16711673.

[17] Cacci E, Ajmone-Cat MA, Anelli T, Biagioni S, Minghetti L (2008). In vitro neuronal and glial differentiation from embryonic or adult neural precursor cells are differently affected by chronic or acute activation of microglia. Glia, 56:412-425.

[18] Wang C, Wang M, Arrington J, Shan T, Yue F, Nie Y, et al. (2017). Ascl2 inhibits myogenesis by antagonizing the transcriptional activity of myogenic regulatory factors. Development, 144:235-247.

[19] Schuijers J, Junker JP, Mokry M, Hatzis P, Koo BK, Sasselli V, et al. (2015). Ascl2 acts as an Rspondin/Wnt-responsive switch to control stemness in intestinal crypts. Cell Stem Cell, 16:158-170.

[20] Scott IC, Anson-Cartwright L, Riley P, Reda D, Cross JC (2000). The HAND1 basic helix-loop-helix transcription factor regulates trophoblast differentiation via multiple mechanisms. Mol Cell Biol, 20:530-541. 